\title{
¿POR QUÉ AIAPAEC Y CHICOPAEC NO SON NOMBRES DE DIOSES?*
}

\author{
WHY ARE IAPAEC AND CHICOPAEC NOT NAMES OF GODS?
}

\author{
Henry Luis Gayoso Rullier ${ }^{1}$
}

\begin{abstract}
Este artículo pretende demostrar, mediante la revisión de "El Arte de la Lengua Yunga" de Fernando de la Carrera y otras fuentes, que los términos mochicas aiapac y chicopæc no eran nombres de divinidades masculinas de las culturas Moche y Chimú, sino más bien epítetos del dios de los conquistadores españoles.
\end{abstract}

Palabras claves: Cultura Moche o Mochica, Aiapaec, divinidades moches, lenguas prehispánicas.

By analyzing Fernando de la Carrera's "Arte de la Lengua Yunga" and other documents, this article attempts to demonstrate that the terms "aiapæc" and "chicopæc" were not names of Moche and Chimú male gods but epithets of the god of the Spaniards conquistadors.

Key words: Moche or Mochica culture, Aiapaec, Moche gods, prehispanic languages.

La cultura Moche o Mochica se desarrolló en la costa norte del Perú entre los siglos I y IX de nuestra era. Los avances de la arqueología a partir de mediados de los años noventa han permitido reconocer al menos dos territorios mochicas, ambos separados por el desierto de Paiján. Los llamados "mochicas del Norte" y "mochicas del Sur" eran políticamente independientes y se diferenciaban en aspectos como la lengua, la arquitectura, los patrones funerarios, la evolución estilística de la cerámica fina, pero compartían un rasgo en común: la religión (Castillo y Donnan 1994; Kaulike 1994; Shimada 1994).

Aunque algunos sustentaron la tesis del monoteísmo moche (cf. Larco 2001 [1939]:350), existe hoy un consenso en cuanto al carácter politeísta de dicha religión cuyo panteón era numeroso y jerarquizado, aunque no hay anuencia sobre las posiciones en dicha jerarquía y las identidades ( $c f$. Bereskin 1983; Golte 1994; Hocquenghem 1989, 1997; Lieske 1992, 2001; Makowski 1994, 1996, 2000, 2005, 2008).

Los diferentes dioses moches han sido identificados gracias a su representación en variados soportes, como muros arquitectónicos, cerámica, objetos de metal, principalmente, así como en algunos tejidos y objetos de otros materiales. $\mathrm{Si}$ bien podemos intentar reconocerlos a partir de las imágenes que nos han dejado los moches en su arte, sus nombres propios no han llegado hasta nosotros.

Uno de estos dioses ha sido considerado como el dios o divinidad primordial de los moches. Krzysztof Makowski lo describe como un dios primordial, pareja de la Mujer Mítica, un anciano y antiguo dios calvo, algo andrógino, rodeado de serpientes monstruosas que le cubren la espalda o constituyen su pelo. Él vive en las entrañas de las cadenas montañosas y "no parece inmiscuirse directamente en los asuntos de los seres humanos, salvo para sembrar caos e inestabilidad" (Makowski 2008:97).

Por su parte, Cristóbal Campana y Ricardo Morales consideran que es la "deidad primordial y suprema para los mochicas", que proviene desde tiempos de los cupisniques, la "de mayor jerarquía en el panteón mochica" y cuyos "rasgos y atributos son la metonimia de las fuerzas de la naturaleza y de la inteligencia humana en poder de la deidad" (Campana y Morales 1997:110-111).

Anne Marie Hocquenguem lo describe como un "poderoso inmortal detentador de la autoridad absoluta, dueño de la vida y de la muerte de todo lo que concibe, anima y ordena con sus tres diferentes fuerzas vitales" (Hocquenghem 1997:236). Ella aventura una analogía entre esta divinidad y Viracocha, pues ambos detienen a las serpientes para

1 Universidad Nacional de Trujillo, Trujillo, Perú. hgayoso@huacasdemoche.pe 
vencer el caos, el pachacuti, y restablecer el orden, marcando el paso de un ciclo a otro (Hocquenghem 1997:236).

Este dios se encuentra representado, por ejemplo, en diferentes espacios arquitectónicos del Templo Viejo de la Huaca de la Luna (Figuras 1 y 2), en el valle de Moche, y del Templo de Cao Viejo, en el valle de Chicama. Su nombre original nos resulta desconocido, pero se le ha llamado a lo largo del tiempo, desde su descubrimiento arqueológico, de diferentes formas: "el degollador", "el decapitador", "el dios de las montañas", e incluso "Aiapaec" o "Ai Apaec". Rafael Larco Hoyle (2001 [1939]) fue el primero en asignar el nombre Ai Apaec a esta deidad de grandes colmillos felinos; pero tal y como resaltan investigadores de diversas épocas como John Rowe y Edward de Bock, la identificación de dicha divinidad con dicho nombre no pasa de ser "simplemente un ejemplo de pensamiento ilusorio ${ }^{1 "}$ (Rowe 1948:5 [traducido por el autor]) y que "carece de argumento científico" (De Bock 2012:I p. 20). A pesar de eso, el teónimo Aiapaec es, hoy en día, muy utilizado en la mochicología -la arqueología de la cultura Moche- $\mathrm{y}$ se ha posicionado fuertemente en el sector turístico.

En 2012 publicamos el primer "Guion de Interpretación del Producto Turístico Huacas de Moche" donde señalamos que el término aiapac, basándonos en el contexto de donde fue extraído, se refiere al dios de los conquistadores españoles y no a una deidad andina (Gayoso 2012:40). En ese entonces, no argumentamos el porqué de nuestra aseveración pues la referida publicación, tal como se puede deducir a partir de su nombre, no estaba orientada en esos términos.

El lingüista José Antonio Salas, en su "Etimologías mochicas", publicada también en 2012, dedica varias páginas a los términos aiapcec y chicopæec. Salas, a partir de un análisis de aspectos formales y de contenido, concluye que tanto los vocablos aiapac como chicopac no son conceptos que tengan connotaciones teológicas autóctonas, sino adjetivos que califican a la divinidad cristiana (Salas 2012:116-122). Salas critica el que Larco, a fin de sostener su tesis del monoteísmo mochica, se pasara por alto una serie de evidencias que apuntaban a

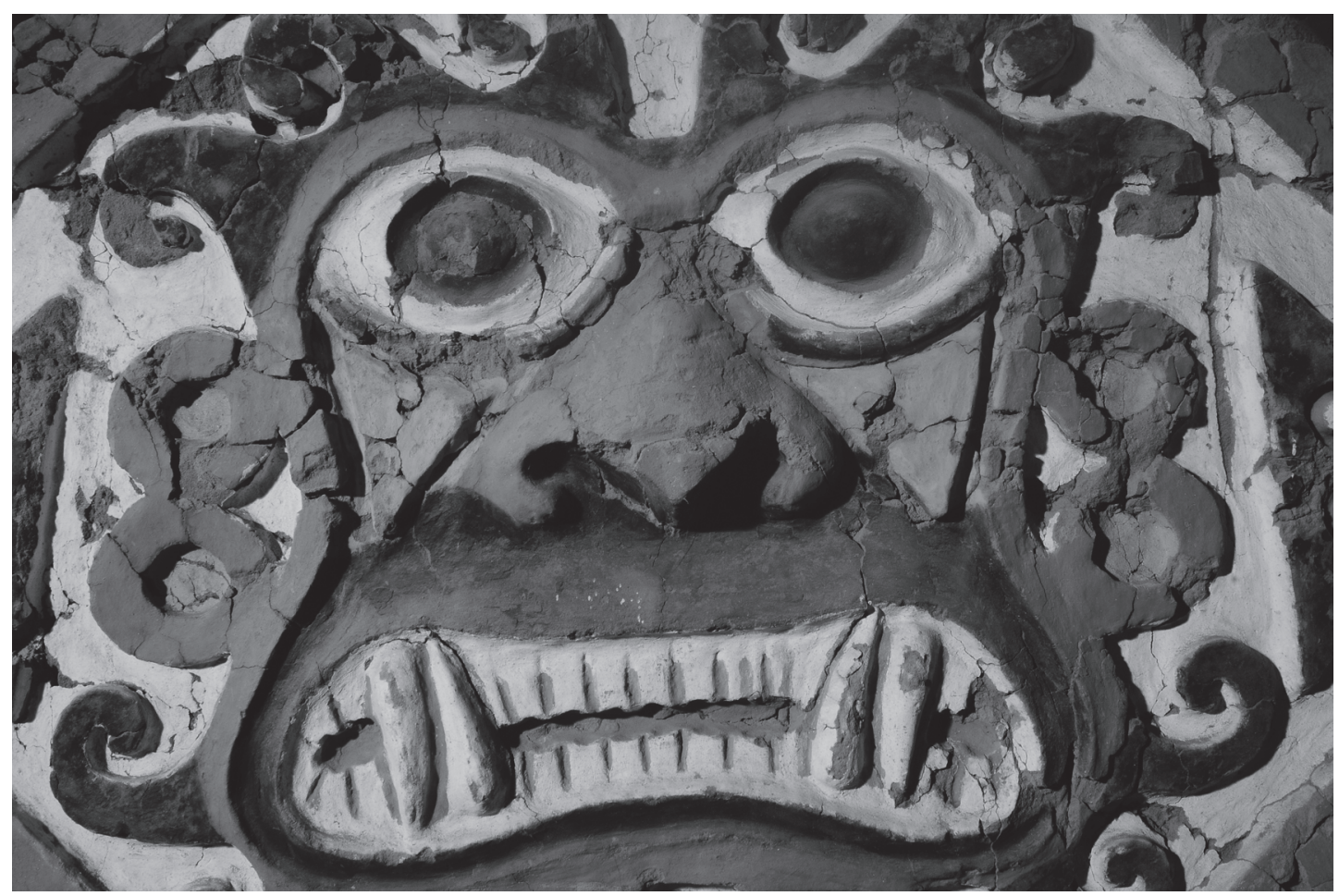

Figura 1. Rostro del dios principal moche en el Patio de los Rombos del Templo Viejo de la Huaca de la Luna. Foto de Heinz Plenge. Face of the Moche main god at the Patio of the Rhombi. Old Temple of Huaca de la Luna. Photo by Heinz Plenge. 


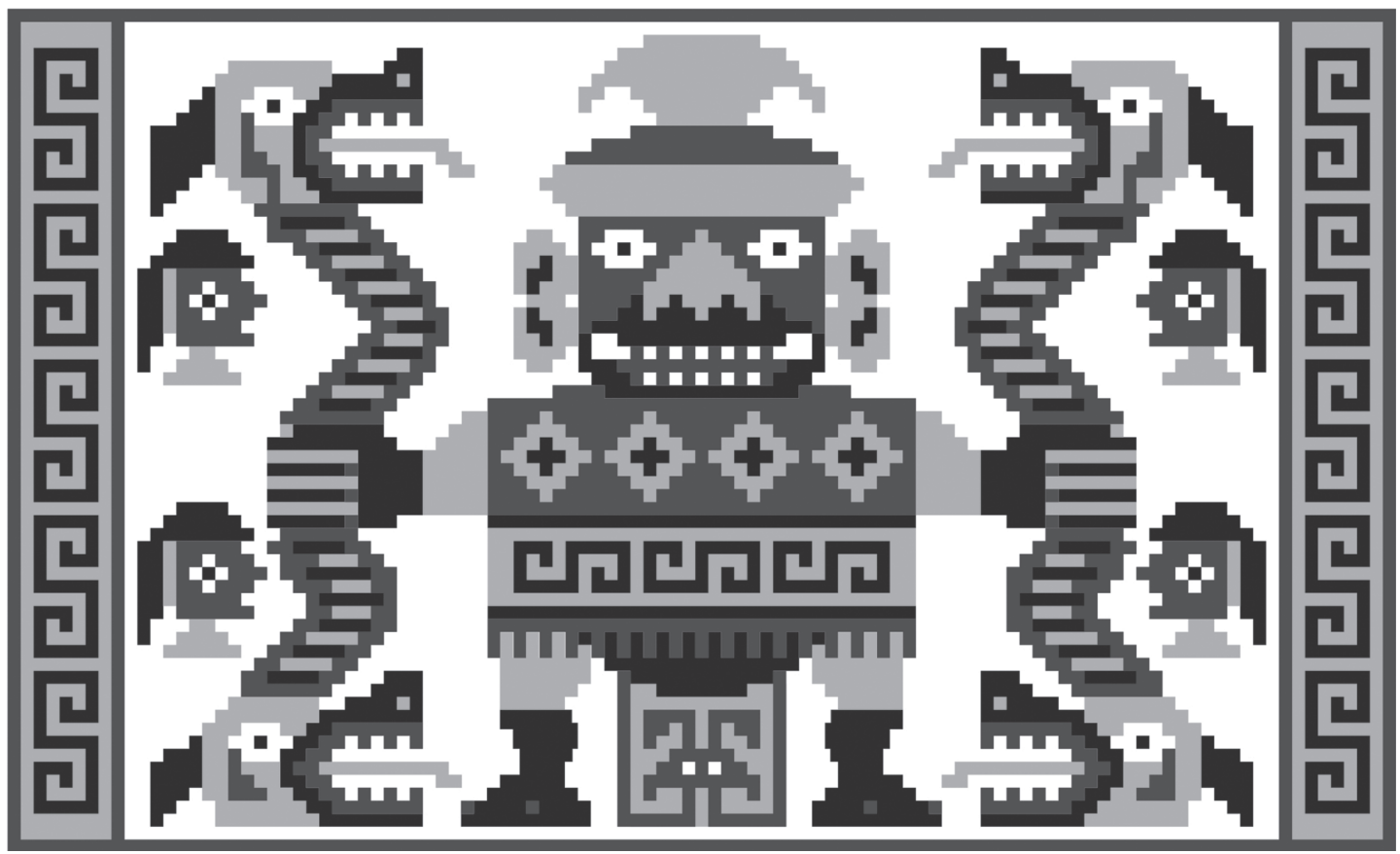

Figura 2. Reconstrucción de un mural del dios primordial en el Patio del Altar Principal del Templo Viejo de la Huaca de la Luna. Dibujo del Proyecto Arqueológico Huacas del Sol y de la Luna.

Reconstruction drawing of a mural depicting the main god at the Great Altar of the Old Temple of Huaca de la Luna. Drawing by Huacas del Sol y de la Luna Archaeological Project.

lo contrario (Salas 2012:118-119). También señala su extrañeza de que, a pesar de que Larco nunca hizo argumentación ontológica alguna sobre esta supuesta deidad mochica, la comunidad científica adoptara el nombre Ai Apaec sin ningún espíritu crítico durante tanto tiempo (Salas 2012:116). A lo señalado por Salas queremos agregar que las críticas que actualmente existen en la literatura especializada son tímidas y sin mayor argumentación.

Bajo todo este contexto, nos sentimos obligados a escribir el presente artículo, desde la perspectiva del arqueólogo e historiador, con la finalidad de esgrimir argumentos que complementan y refuerzan lo expuesto por Rowe, De Bock y, principalmente, Salas.

\section{De Dónde Provienen los Nombres Aiapaec y Chicopaec}

Gracias a los cronistas, sabemos que en la zona centroandina se hablaba un gran número de lenguas y dialectos. Por ejemplo, para la costa norte del actual territorio del Perú, se registran de norte a sur las lenguas de Sechura y las del grupo tallán (lenguas de Colán y Catacaos), que el padre Antonio de la Calancha llamó en conjunto lengua Sec "por confusión o desconocimiento" (Torero 1986:524), la lengua de Olmos, la lengua mochica (o muchic según De la Calancha), y la lengua quingnam. La llamada lengua pescadora podría ser otra forma de designar a la lengua quingnam, o ambas podrían ser dos dialectos de una misma lengua (CerrónPalómino 1995:31).

Todas ellas son lenguas muertas o extintas, en el sentido de que ya no son lengua materna de ninguna comunidad de hablantes. Solo la lengua mochica "recibió los honores de la imprenta" (Torero 1986:524) durante la Colonia. En el año 1607 se imprimió la obra "Rituale seu Manuale" de Gerónimo de Oré, donde se incluyen cuatro páginas de oraciones católicas y catecismo en lengua mochica (Torero 1986:524). En 1644 se imprimió el "Arte de la lengua Yunga" del padre Fernando de la Carrera; de esta última obra trataremos más adelante. No tuvieron la misma suerte las otras lenguas mencionadas.

Hasta fines del siglo XVII, las lenguas mochica y quingnam fueron las más comunes en los valles 
de la costa norte, a tal punto que con ellas "se manejava el mucho comercio i las contrataciones destos territorios" (De la Calancha 1974-81 [1638]:3, cap. II). Alfredo Torero afirma que debe entenderse por "más comunes" (Torero 1986:533) como las más extendidas en el territorio norcosteño.

Ambas lenguas tuvieron una frontera lingüística compuesta por los territorios costeros de los valles de Chicama y Jequetepeque donde coexistían grupos hablantes de una y otra lengua (Cerrón-Palomino 1995; Torero 1986). De acuerdo con los datos proporcionados por Fray Reginaldo de Lizárraga, en el valle de Chicama se hablaban dos lenguas: la pescadora "dificultosísima, y otra no tanto" (De Lizárraga 1968 [1605]: cap. XVI), probablemente refiriéndose a la mochica. Según Rubén Vargas Ugarte (en Netherly 1977:337) y el padre agustino Antonio de la Calancha (1974-81 [1638]:3, cap. II), la lengua mochica se hablaba desde Motupe hasta Pacasmayo (valle de Jequetepeque), pero también más al sur, en dos doctrinas del valle de Chicama: Paiján y Chocope. La quingnam o pescadora, por su parte, se hablaba desde Pacasmayo, pasando hasta Lima.

Sin embargo, De la Carrera (1939 [1644]:7) considera como zonas de habla mochica en el valle de Chicama, además de Chocope y Paiján, a Santiago de Santo Domingo (que sería el actual Santiago de Cao, reducción entonces regentada por un curato de padres dominicos) y La Magdalena de Cao. Si bien existe la posibilidad de que el padre De la Carrera se haya equivocado al considerar Magdalena y Santiago de Cao como zonas de habla mochica, también es posible que, dado que Magdalena y Santiago de Cao eran reducciones compuestas por numerosas parcialidades, algunas hablaran mochica y otras quingnam. José Antonio Salas (2012:23-24) recoge información proporcionada por algunos cronistas, además de la existencia de la acequia conocida ya en 1581 como "La Mochica", para afirmar que la frontera lingüística debería ampliarse más al sur, hasta la zona de Trujillo. Sin embargo, según Waldemar Espinoza, la presencia mochica en el valle de Moche se reduciría a una "insignificante agrupación de mitimas mochicas" (Espinoza 1975:248).

La lengua quingnam era hablada por el grupo cultural conocido arqueológicamente como Chimú, principalmente en los territorios costeños de los valles de Chicama, Moche, Virú, Chao y Santa. Si tenemos en cuenta que los moches que ocupaban el territorio al sur del desierto de Paiján son los antecesores de los chimúes, no solo en términos culturales y de ocupación del territorio nuclear (valle de Moche), sino también en términos de consanguinidad, es válido afirmar que el quingnam fue hablado también por los moches "sureños".

Hemos resaltado la existencia de una frontera lingüística compartida porque, si bien los vocablos aiapac y chicopac han sido registrados en un documento que trata sobre la lengua mochica, no existe ninguna evidencia que indique que dichos vocablos no figuraban en el idioma quingnam; tampoco existe evidencia que demuestre lo contrario. Pero independientemente de su origen lingüístico ¿son los vocablos aiapac y chicopac nombres de antiguos dioses? Vamos a argumentar que no.

En la literatura especializada, dos son los investigadores que han identificado originalmente a Aiapaec (o Ai Apaec) y Chicopaec como dioses mochicas: Rafael Larco y María Rostworowski. Rafael Larco, en el tomo II de su obra monumental "Los Mochicas" (Larco 2001 [1939]), dedica un capítulo entero a la religión mochica, a la que ve como "una elucubración espiritual elevada. La que más se acercó a la perfección y la que más fuerza espiritual tuvo", pero que lamentablemente las nuevas culturas, "por causas todavía no establecidas, le restaron potencialidad" (Larco 2001 [1939]:272). Según Larco, la religión mochica evoluciona desde las sociedades anteriores, zoólatras, que encuentran en las diferentes características del felino la mejor forma de representar el poder en todas sus formas, el poder que rige el mundo. Con los moches, la humanización del felino llega a su máxima expresión, perfeccionándose como divinidad, y transformándose "en la imagen de principal veneración del pueblo mochica" (Larco 2001 [1939]:272). Larco ve en la "felinidad" el símbolo único del ser supremo que está sobre todas las cosas. Identifica entonces a Ai Apaec como el hacedor, el ser supremo, pero también como "la encarnación del ser supremo en el hombre", "el superhombre, cuyos atributos divinos fueron objetos de pleitesía y adoración de los demás", aquel que se forja "para establecer el contacto con el ser supremo" (Larco 2001 [1939]:273). Larco distribuye entonces "la concepción religiosa mochica en dos personas: la abstracta y la humana" (Larco 2001 [1939]:273), y marca una analogía con la religión católica, pues Ai Apaec constituiría una especie de "misterio de divina dualidad", donde sería tanto el dios supremo, abstracto, inmaterial, espiritual, como su materialización en un ser antropomorfo con 
rasgos felinos, el intermediario entre los hombres y un ser supremo, la "materialización divina para poder venerar y adorar al supremo omnipotente que no comprende" (Larco 2001 [1939]:273).

Uno podría preguntarse por qué Larco tomaría una palabra de la lengua mochica para referirse a un dios que identifica a partir de piezas arqueológicas extraídas principalmente en valles de habla quingnam. La razón podría basarse en la idea generalizada que se tenía en la época que yunga, mochica, quingnam y pescadora eran formas diferentes de llamar a una misma lengua, "o, en todo caso, dialectos de un mismo idioma” (Cerrón-Palomino 1995:36). Esta idea se vería reforzada por la noción, vigente hasta inicios de los noventa, de lo Mochica como una sola entidad política, ocupando la mayor parte de la costa norte del actual territorio peruano, con el poder político, económico e ideológico centralizado en su capital, la ciudad de las Huacas del Sol y de la Luna.

Décadas más tarde, María Rostworowski, quizás influenciada por Larco, señalaría a dos divinidades “chimú-mochica": Chicopaec, el criador, y Aiapaec, el hacedor" (Rostworowski 2000:59). Ambas divinidades serían "una dualidad cosmogónica masculina, disimulada por la necesidad de los sacerdotes cristianos de hallar dioses creadores" (Rostworowski 2000:59). Para Rostworowski, probablemente "Aiapaec fuese una divinidad celeste, agrícola, relacionada con el poder y la influencia del Sol sobre las plantas, los animales y los hombres" mientras que Chicopaec sería "un soplo vital que mantenía vivo todo lo existente" (Rostworowski 2000:59-60).

Ambos, Larco (2001 [1939]) y Rostworowski (2000) consideran de manera implícita y explícita que Aiapaec es un dios moche y chimú, es decir, un dios que ha tenido vigencia en la ideología norcosteña, por lo menos desde inicios de nuestra era hasta el siglo XVII, ya en época colonial. La fuente de donde extrajeron Larco y Rostworowski los términos aiapaec (aipac) ${ }^{2}$ y chicopaec (chicopac) fue la obra del siglo XVII mencionada líneas arriba. En el año 1644, el licenciado don Fernando de la Carrera Daza, entonces cura y vicario del pueblo de San Martín de Reque, en la jurisdicción de Chiclayo, escribió el "Arte de la lengua Yunga", "la lengua más general y más elegante de los Indios de los valles" (De la Carrera 1939 [1644]:3) del obispado de Trujillo, que no es otra que la lengua mochica ${ }^{3}$.

De la Carrera, aunque nacido en Trujillo, aprendió esta lengua durante su niñez "en el Pueblo de Lambayeque, adonde me crié..." (De la Carrera 1939 [1644]:6). Esta obra, elaborada para uso de los curas con el objeto de "dar a entender [a los indios] en su lengua lo que la doctrina contiene, para que la reciban, y aprehendan con fervor y amor, y no la sepan como oración de ciego" (De la Carrera 1939 [1644]:6) estaba compuesta por un tratado de gramática de dicha lengua, con su respectiva pronunciación graficada mediante símbolos fonéticos, acompañado eventualmente de pequeños glosarios de verbos y vocablos y, finalmente, de los diferentes rezos y cánticos que se efectuaban en las misas, de su original en latín traducidos al mochica.

Los vocablos aipac 'hacedor' y chicopac 'criador' se encuentran, por ejemplo, dentro de un pequeño glosario sobre el uso de los nombres con los genitivos (Figura 3). Este glosario forma parte de un cuadernillo de vocablos y verbos, adverbios y conjunciones de todo el confesionario católico de la época. El título del acápite reza "Cuadernillo

\section{LOS NOMBRES SE PONEN CON LOS GENITIVOS}

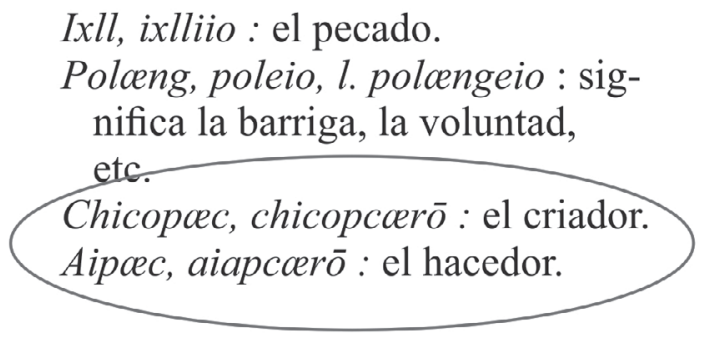

\author{
Coefoer, coefoeréio : el trueque o \\ paga de alguna cosa, o lugar- \\ teniente de otro. \\ Eiñ ciñ, iñ iño : quien quiera. \\ Eiz, eizieio, l. èizien : el hijo o \\ hija.
}

Figura 3. Fragmento del Arte de la Lengua Yunga del padre Fernando de la Carrera Daza (1939 [1644]:68) donde se observan los vocablos chicopac y aipac.

The terms chicopæc and aipæc in an extract of Fernando de la Carrera's Arte de la Lengua Yunga (1939 [1644]:68). 
de los vocablos y verbos, adverbios y conjunciones de todo el confesionario, que está después de este cuadernillo, para que mejor se entienda" (De la Carrera 1939 [1644]:68).

Pero estos vocablos no solamente se encuentran en dicho glosario, sino también en algunos rezos y cánticos del libro. Así, el vocablo aipaec se encuentra en el Credo (Credo in Deum ${ }^{4}$, Figura 4), en la Confesión $\mathrm{General}^{5}$, entre otros.

También hemos encontrado los vocablos funocopæe, que quiere decir "sustentador" (Figura 5), y caix copac, que quiere decir "sostenedor" (Figura 4) según Rodolfo Cerrón-Palomino, aunque él cita caxcópuc del anónimo Oré (Cerrón-Palomino 1995:99), que en todo caso parece ser la palabra escrita tal como se pronuncia aproximadamente.

¿Son funocopac y caix copaec también teónimos o nombres de dioses? Pensamos que no, y llamamos la atención en estos vocablos para argumentar que todos ellos, sin excepción, son en realidad epítetos o adjetivos del dios católico (hacedor, creador, sustentador, sostenedor), se encuentran dentro de oraciones católicas traducidas al mochica en una obra de intención eminentemente doctrinal y, por lo tanto, no se refieren a ninguna divinidad indígena en particular cuyo nombre haya sido utilizado por De la Carrera como sinónimo de Dios, por un afán evangelizador.

Es cierto que la sustitución del vocablo "dios" por teónimos autóctonos fue una estrategia de la evangelización de inicios de la Colonia. De hecho, César Itier nos señala que a inicios de la colonización en toda América, se acostumbraba "predicar el cristianismo nombrando a Dios con un teónimo indígena que se creía dotado del mismo significado" (Itier 2013:18) pues había varias razones para

\section{CREDO IN DEUM}

Lli queiñ Dios ef quic, ech ech aipcec, cuşia, ceiz caix copcec, aiescen lliqueiñ oncesco siornaio siung eiz, inceich siec lesu Christo canang pceccedo, Espiritu Santong ssap maen, eng e polenic, namtop que muno Santa Mariang pol en quichn Ponsio Pilatong ssap moen rronom sce ñontop. Cruzcer capcec quessaec top, siung capcec lamtop, xllang cemtop, altop olo infiernong nic, soc luncer nico choc top, loemoedceno chip car lucy quich, puytop cusiang, nic, feltop ech, ech, aia peeco, ong xlloem ef quicar maecyce, cini chofta choem mix, siamoeno, loemoedreno chipecer chiçer temoed. Lliqueiñ scen Espiritu Santo, tzhio poenaio Dios paen, aiescen eiñ xam centa ixllo moeich eng Santa Iglesia, aieçen eiñ xam, tzhio panaio izşec santong peño chiçer, aieçen eiñ capcan ixlloess ef quec scer, aiescen cerqueng e cho quiccer, aieccen eiñ cap can, şio tu ning nico exllec aco siamo chiscec. Amen.

Figura 4. Fragmento del Arte de la Lengua Yunga del padre Fernando de la Carrera Daza (1939:91 [1644]) donde se observa el Credo traducido al muchik, y la presencia de los vocablos aipac (hacedor) y caix copaec (sostenedor) en la primera línea de la oración.

First sentence of The Creed translated to Muchik where it is possible to see the terms aipæc (doer) and caix copæc (supporter). Extract of Fernando de la Carrera's (1939 [1644]:91) Arte de la Lengua Yunga.

y otros algunos, que retienen la $c$. Los participios acabados en pcec, cuando son nombres substantivos, no guardan esa regla, antes es necesario añadirles estas letras cess, para decir mi criador, mi sustentador, mi abogado, etc. Y así de chicopcec, chicopceccess; de funocopcec. funocopcescess; de capcecnemcpкec, apcecnemcpcecsoess, etc.

Figura 5. Fragmento del Arte de la Lengua Yunga del padre Fernando de la Carrera Daza (1939 [1644]:14) donde se observa la presencia del vocablo funocopac y su significado como "sustentador", uno de los epítetos usados para el dios cristiano.

The term funocopæc (sustainer), one of the ephitets of the Christian God, in an extract of Fernando de la Carrera's (1939 [1644]:14) Arte de la Lengua Yunga. 
pensar que "era ineficaz explicar el nombre español 'Dios"” (Itier 2013:19) a los indígenas. ¿Por qué era ineficaz? Itier resalta las siguientes razones: (1) "porque los indios no lo conocían ni lo entendían", (2) porque "nombrar a Dios con el término que tenía ese significado en la lengua indígena facilitaba la sustitución de la concepción autóctona de la divinidad por la concepción cristiana" y (3) porque presentaba al cristianismo "no como una religión totalmente nueva y extraña, sino como la continuación y la culminación de un progreso intelectual que ya se había iniciado en la cultura autóctona" (Itier 2013:19). Este pensamiento se basaba en el supuesto de que existía en las culturas autóctonas “un concepto de 'Dios' o de Hacedor, lo que era, como hemos visto, una evidencia para la mayoría de los primeros evangelizadores" (Itier 2013:19). El ejemplo más estudiado es el de Viracocha, teónimo que fue utilizado para designar tanto a Dios como a Cristo por los evangelizadores.

Sin embargo, esta posición fue abandonada luego del primer concilio de Lima (1551-1552), en el cual se dispuso que "no debía presentarse al cristianismo como la culminación de una evolución espiritual iniciada antes de la Conquista, sino como un aporte radicalmente nuevo" (Itier 2013:21). Entonces, por ejemplo, a partir de ese Concilio, "ya no era posible el empleo de 'Viracocha' como sinónimo de 'Dios' en la predicación" (Itier 2013:22).

El "Arte de la lengua Yunga" fue escrito casi un siglo después del primer concilio de Lima, es decir, corresponde a un momento de la Colonia donde ya se había abandonado la costumbre de reemplazar el vocablo Dios por teónimos de las diferentes culturas autóctonas americanas. Entonces, no se puede argumentar que, como estrategia doctrinal, lo que quiso De la Carrera fue utilizar un teónimo del idioma mochica que se pudiese traducir como "dios", que les fuese familiar a los indios adoctrinados en la lengua mochica. Además, si uno revisa el Arte se puede dar cuenta de ello. Por ejemplo: el primer mandamiento católico planteado como una pregunta en el confesionario como “AAmas a Dios sobre todas las cosas?" es traducido por De la Carrera como “¿Chizpa cyceco Dios izaccech ech lequich?" (de la Carrera 1939 [1644]:75 [el subrayado es nuestro]). Lo mismo se puede apreciar en los rezos contenidos en el Arte. La palabra "dios" no es traducida y se conserva como tal en toda la obra.

Hay otras obras de la época y posteriores en las que también se observa este comportamiento.
Por ejemplo, en aquellas de Luis Jerónimo de Oré (1598) y de Diego de Torres Rubio (1619, 1754). En dichas obras, en el Credo traducido al quechua se observan, al inicio de la oración, los vocablos “dios" y "Iesu Christo" (Jesuscristo) sin traducción: "Yñinim Dios yaya llapa atipacman, hanacpachap, cay pachap ruraquenman. Iesu Christo paypa çapay churin apun chikmanpas Caymi Spiritu Janctomanta runa tucurcan" [los subrayados son nuestros].

En esta misma oración se observa que el término “criador" (creador) es reemplazado por el término "hacedor", "por no aver en esta Lengua Verbo que signifique Criar, que en el rigor philosofico es hacer de la nada" (Torres Rubio 1754:56); así mismo, "hacedor" es traducido como "ruraquenman", dentro de la frase "hacedor del cielo y de la tierra" (hanacpachap,cay pachap ruraquenman)... y Ruraquenman no corresponde a ningún nombre de divinidad andina.

Otro ejemplo es el "acto de contrición” (Torres Rubio 1619:16). La frase inicial reza en español: "Dios todopoderoso, caritativo, mi creador..." y que Torres traduce como "Llapa atipac $\underline{\text { Dios, }}$, cuyapayac, camaquey....". En esta oración también observamos que el vocablo "dios" no ha sido traducido, y que la frase "Mi criador" es traducida como camaquey, palabra que tampoco corresponde a ningún teónimo andino.

Bajo estos argumentos, consideramos que no es correcto denominar con los nombres Aiapaec o Chicopaec a cualquier deidad, ni mochica ni chimú. En ese sentido, creemos que no es correcto llamar Aiapaec al personaje representado, por ejemplo, en el Patio de los Rombos del Templo Viejo de Huaca de la Luna (Figura 1) y en otros espacios arquitectónicos del mismo (Figura 2).

\section{El Dios es la Montaña}

No existe forma conocida de afirmar cuál es el nombre original de este dios. Si bien gracias a las crónicas conocemos los nombres de dos dioses costeños que entran en la categoría de primordiales -Pachacamac y Con- no existe evidencia que nos permita afirmar con certeza que alguno de estos $\mathrm{u}$ otro fue el nombre del dios primordial moche. ¿Cómo llamar a este dios entonces?

Descartando la posibilidad de llamarlo por su nombre original, solo nos queda resaltar el uso de un sobrenombre ya utilizado por algunos investigadores, a partir de la relación iconográfica 
de este dios con la montaña. Edward de Bock lo llama "dios de la montaña" (De Bock 2003:312). Kzrysztof Makowski lo identifica como el Dios de las Montañas, o el Dios de los Cerros (Makowski 2008:97), o el Señor de la Tierra (Makowski 2008:103). Santiago Uceda concuerda en identificar a este dios como el Dios o Divinidad de las Montañas (Uceda 2008:117). Creemos que "el Dios de las Montañas" es una de las formas más apropiadas de llamarlo, toda vez que en algunas vasijas de cerámica registradas en el sitio arqueológico $^{6}$, se representa a este dios formando parte de la montaña, o siendo la montaña misma, acompañado de dos serpientes, rodeando su espalda (Figura 6). Sin embargo, debemos dejar en claro que su asociación con la montaña es uno de los tantos rasgos de este dios y, por lo tanto, esta nominación de Dios de las Montañas no deja de ser arbitraria.

Lo que nos interesa por encima de cualquier sobrenombre que le podamos asignar a este dios, es dejar en claro la naturaleza de términos como aiapaec y chicopaec, tradicionalmente reconocidos como los nombres propios de una dualidad de dioses mochicas-chimúes. Somos conscientes de que Aiapaec es un nombre que se ha posicionado en el campo académico y turístico, pero consideramos necesario llamar la atención al hecho de que, como hemos intentado demostrar en este artículo, el vocablo aiapac (hacedor) no es el nombre propio de algún dios, sino uno de los tantos epítetos o adjetivos con los que se resalta o ensalza en los rezos al dios de la religión cristiana traída por los conquistadores españoles, y traducidos, entre otros idiomas, al mochica, como también es el caso de los epítetos chicopac (criador), funocopac (sustentador) y caixcopac (sostenedor).

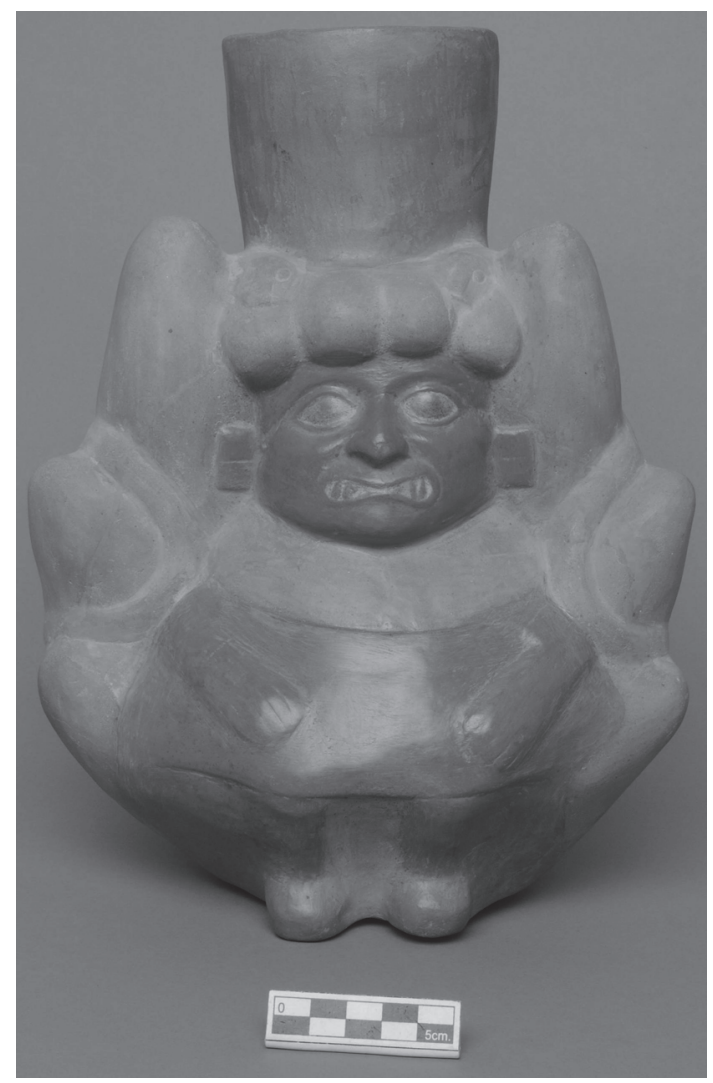

Figura 6. Representación en cerámica del dios siendo parte de la montaña. Museo Huacas de Moche. Foto de Nadia Gamarra. Ceramic vessel depicting the god being a part of the mountain. Huacas de Moche Museum. Photo by Nadia Gamarra.

Agradecimientos: a los doctores Santiago Uceda y Luis Jaime Castillo, a los editores y a los evaluadores anónimos, por sus comentarios y sugerencias para mejorar este artículo.

\section{Referencias Citadas}

Bereskin, Y.E. 1983. Mochica. Die Zivilisation der Indianer des nördlichen Küstenstreifens von Peru im 1-7. Jahrhundert, Leningrad.

Campana, C. y R. Morales 1997. Historia de una Deidad Mochica. A \& B S. A, Lima.

Cerrón-Palomino, R. 1995. La Lengua de Naimlap (Reconstrucción y Obsolencia del Mochica). Fondo Editorial de la Pontificia Universidad Católica del Perú, Lima.

Castillo, L.J. y C. Donnan 1994. Los mochicas del norte y los mochicas del sur, una perspectiva desde el valle de Jequetepeque. En Vicús, editado por K. Makowski, pp. 143-181. Colección Arte y Tesoros del Perú, Banco de Crédito del Perú, Lima.
De Bock, E.K. 2003. Templo de la escalera y ola y la hora del sacrificio humano. Actas del Segundo Coloquio sobre la cultura Moche. Moche: hacia el final del milenio, editado por S. Uceda y E. Mujica, tomo I, pp. 307-324. Universidad Nacional de Trujillo y Pontificia Universidad Católica del Perú, Lima.

- - - 2012. Sacrificios Humanos. Para el Orden Cósmico y la Regeneración. Estructura y Significado en la Iconografía Moche. Editor L. Valle Álvarez. Traducido por C.A. Gálvez Mora. Ediciones Sian, Trujillo.

De la Calancha, A. 1974-81 [1638]. Cronica Moralizada del Orden de San Agustin en el Peru, con Sucesos Egenplares en esta Monarquia Tomo 4: 1223-1672. Editado por Ignacio Prado Pastor, Lima. 
De la Carrera, F. 1939 [1644]. Arte de la Lengua Yunga. Reeditado por Radames A. Altieri, Departamento de Investigaciones Regionales, Instituto de Antropología, Universidad Nacional de Tucumán. Publicación No 256, Tucumán.

De Lizarraga, R. 1968 [1605]. Descripción Breve de Toda la Tierra del Perú, Tucumán, Rio de La Plata y Chile. Biblioteca de Autores Españoles, tomo 216. Ediciones Atlas, Madrid.

De Oré, L.J. 1598. Orden de Enseñar la Doctrina Cristiana en las Lenguas Quichua y Aymara. http://www.unileiden.net/ore/ ore_pdf/text-t/text-t-quechua_ore.pdf (27 de abril de 2013).

De Torres Rubio, D. 1619. Arte de la Lengva Qvichva. Editado por Francisco Lasso, Lima.

De Torres Rubio, D. 1754. Arte y Vocabulario de la Lengua Quichua General de los Indios de el Perú. Editado por Francisco Lasso, Lima.

Espinoza Soriano, W. 1975. El valle de Jayanca y el reino de los Mochica, siglos XV y XVI. Bulletin de l'Institut Française de Études Andines IV (3-4):243-274.

Gayoso Rullier, H.L. 2012. Producto Turístico Huacas de Moche: Guion de Interpretación. Primera edición, Patronato Huacas del Valle de Moche, Fondoempleo, Backus, Universidad Nacional de Trujillo y Worlds Monuments Fund, Trujillo.

Golte, J. 1994. Iconos y Narraciones: la Reconstrucción de una Secuencia de Imágenes Moche. Serie Fuentes e investigaciones para la Historia del Perú 10, primera edición. IEP ediciones, Lima.

Hocquenghem, A.M. 1989. Iconografía Mochica. Tercera edición. Fondo Editorial Pontificia Universidad Católica del Perú, Lima.

- - - 1997. Como una imagen del otro lado del espejo. Memoria para el futuro: una visión del orden del mundo andino. Actas de las VI Jornadas del Inca Garcilaso. Pensar americano. Cosmovisión mesoamericana y andina, compilado por A. Garrido Aranda, pp. 215-247. Colección MAYOR, coedición de Caja Sur Publicaciones y el Ayuntamiento de Montilla, Córdoba.

Itier, C. 2013. Viracocha o el Océano. Naturaleza y Funciones de una Divinidad Inca. Colección Mínima Nº6. Instituto Francés de Estudios Andinos, Lima.

Kaulicke, P. 1994. La presencia mochica en el Alto Piura: problemática y propuestas. Moche: propuestas y perspectivas. Actas del Primer Coloquio sobre la Cultura Moche Travaux de l'Institute Français d'Etudes Andines, editado por S. Uceda y E. Mujica, 79:327-358. Universidad de La Libertad - Trujillo, Instituto Francés de Estudios Andinos y Asociación Peruana para el Fomento de las Ciencias Sociales, Lima.

Larco Hoyle, R. 2001 [1939]. Los Mochicas. Tomo II, Museo Arqueológico Rafael Larco Herrera, Lima.

Lieske, B. 1992. Mythische Erzaehlungen in den Gefaessmalereien der Altperuanischen Moche-Kultur. Versuch einer ikonographischen Rekonstruktion. Holos Verlag, Bonn.
- - - 2001. Göttergestalten der Altperuanischen MocheKultur. Veröffentlichungen der Projektgruppe Ikonographie am Lateinamerika-Institut der Freien Universität, band 1, Berlin.

Makowski, K. 1994. La figura del oficiante en la iconografía mochica: ¿shaman o sacerdote? En En el Nombre del Señor: Shamanes, Demonios y Curanderos del Norte del Perú, editado por L. Millones y M. Lemlij, pp. 52-95. Biblioteca Peruana de Psicoanálisis, Seminario Interdisciplinario de Estudios Andinos, Lima.

_ - _ 1996. Los seres radiantes, el águila, el búho: la imagen de la divinidad en la cultura Mochica (siglos II - VIII d.C.) En Imágenes y mitos. Ensayos sobre las artes figurativas en los Andes prehispánicos, pp. 13-114. Colección Ars Historiae, segundo título, Australis S.A. Casa Editorial, Fondo Editorial Sidea, primera edición, Lima.

- - - 2000. Las divinidades en la iconografía mochica. En Los Dioses del Antiguo Perú, editado por K. Makowski, pp. 137175. Colección Arte y Tesoros del Perú, Banco de Crédito del Perú, Lima.

- - - 2005. Hacia la reconstrucción del panteón moche: tipos, personalidades iconográficas, narraciones. En El Mundo Sobrenatural Mochica. Imágenes Escultóricas de las Deidades Antropomorfas en el Museo Arqueológico Rafael Larco Herrera, editado por M. Giersz, K. Makowski y P. Przadka, pp. 3-101. Fondo Editorial de la Pontificia Universidad Católica del Perú, Lima.

- - - 2008. El rey y el sacerdote. En Señores de los Reinos de la Luna, compilado por K. Makowski, pp. 77-109. Banco de Crédito, Lima.

Netherly, P.J. 1977. Local Level Lords on the North Coast of Peru. Tesis de doctorado. Cornell University. Nueva York.

Rostworowski, M. 2000. Estructuras Andinas del Poder. Cuarta reimpresión, Instituto de Estudios Peruanos, Lima.

Rowe, J.H. 1948. The kingdom of Chimor. Acta Americana VI 1-2:26-59, México.

Salas García, J. A. 2012. Etimologías Mochicas. Primera edición. Academia Peruana de la Lengua, Lima.

Shimada, I. 1994. Los modelos de la organización sociopolítica de la cultura Moche. Moche: propuestas y perspectivas. Actas del Primer Coloquio sobre la Cultura Moche Travaux de l'Institute Français d'Etudes Andines, editado por S. Uceda y E. Mujica 79:359-387. Universidad de La Libertad - Trujillo, Instituto Francés de Estudios Andinos y Asociación Peruana para el Fomento de las Ciencias Sociales, Lima.

Torero, A. 1986. Deslindes lingüísticos en la costa norte peruana. Revista Andina 2:523-548. Centro de Estudios Rurales Andinos "Bartolomé de las Casas", Cusco.

Uceda, S. 2008. En busca de los palacios de los reyes de Moche. En Señores de los Reinos de la Luna, compilado por K. Makowski, pp. 111-127. Banco de Crédito, Lima.

\section{Notas}

* Proyecto Arqueológico Huacas del Sol y de la Luna.

1 En el original en inglés "...merely a piece of wishful thinking". El pensamiento ilusorio (wishful thinking) es el proceso de pensamiento, deducción, conclusión y toma de decisiones basadas en lo que sería más placentero de imaginar en vez de comprobarlas, fundamentarlas en la evidencia o racionalidad (http://es.wikipedia.org/wiki/ Pensamiento_ilusorio). 
2 De acuerdo con F. de la Carrera, se pronunciaría casi como "aiapuc" pues la vocal æ "tiene principio de e y fin de u" (De la Carrera 1939 [1644]:11).

3 Cuando F. de la Carrera habla de la lengua yunga, claramente se refiere a la lengua mochica. En su Arte hay varias evidencias de ello: (1) la primera aprobación del Arte la da el bachiller Jacinto de Miranda, cura de Lambayeque y Comisario del Santo Oficio en la jurisdicción de Zaña, ambas zonas de habla mochica (De la Carrera 1939 [1644]:1); (2) la censura que hace del Arte el padre Fr. Marcos García, "eminente en la lengua yunga que se conoce" (De la Carrera 1939
[1644]:2) y cura de Mocupe, zona de habla mochica; (3) la segunda aprobación que hace del Arte el licenciado Juan Niño de Velasco, cura rector de la Santa Iglesia parroquial de Zaña y "muy lenguaraz de la lengua mochica" (De la Carrera 1939 [1644]:2).

4 "Lli queiñ Dios ef quic, ech ech aipac, cuçia, aiz caix copac,..." (De la Carrera 1939 [1644]:91).

5 "Ixllas eiñ mañap, ech aipaco Dios tot,". (De la Carrera 1939 [1644]:91).

6 Cuatro de estas vasijas se encuentran en exhibición en el Museo Huacas de Moche, en la primera sala. 